\title{
Rapid and mobile determination of alcoholic strength in wine, beer and spirits using a flow-through infrared sensor
}

\author{
Dirk W Lachenmeier*1, Rolf Godelmann¹, Markus Steiner², Bob Ansay², Jürgen Weigel² and Gunther Krieg²
}

\begin{abstract}
Background: Ever since Gay-Lussac's time, the alcoholic strength by volume (\% vol) has been determined by using densimetric measurements. The typical reference procedure involves distillation followed by pycnometry, which is comparably labour-intensive and therefore expensive. At present, infrared (IR) spectroscopy in combination with multivariate regression is widely applied as a screening procedure, which allows one to determine alcoholic strength in less than 2 min without any sample preparation. The disadvantage is the relatively large investment for Fourier transform (FT) IR or near-IR instruments, and the need for matrix-dependent calibration. In this study, we apply a much simpler device consisting of a patented multiple-beam infrared sensor in combination with a flow-through cell for automated alcohol analysis, which is available in a portable version that allows for on-site measurements.

Results: During method validation, the precision of the infrared sensor was found to be equal to or better than densimetric or FTIR methods. For example, the average repeatability, as determined in 6 different wine samples, was $0.05 \%$ vol and the relative standard deviation was below $0.2 \%$. Accuracy was ensured by analyzing 260 different alcoholic beverages in comparison to densimetric or FTIR results. The correlation was linear over the entire range from alcohol-free beers up to high-proof spirits, and the results were in substantial agreement $(R=0.99981, p<0.0001$, RMSE $=0.279 \%$ vol). The applicability of the device was further proven for the analysis of wines during fermentation, and for the determination of unrecorded alcohol (i.e. non-commercial or illicit products).
\end{abstract}

Conclusions: The flow-through infrared device is much easier to handle than typical reference procedures, while timeconsuming sample preparation steps such as distillation are not necessary. Therefore, the alcoholic strength can be economically and quickly controlled (requiring less than 60 s per sample). The device also gives the opportunity for mobile on-site control in the context of labelling control of wine, beer and spirits, the process monitoring of fermentations, or the evaluation of unrecorded alcohols.

\section{Background}

The alcoholic strength expressed in percent by volume (\% $\mathrm{vol}$ ) is one of the oldest parameters for which quantitative analytical methods have been developed, and is still determined in businesses and laboratories around the world. The foundations for the determination of alcoholic strength were laid by Gay-Lussac by inventing not only a simple-to-use centesimal alcoholometer (i.e. a hydrometer with a '\% vol' scale) but also by providing the theoretical background in his 1824 monograph 'l'alcoomètre

* Correspondence: lachenmeier@web.de

${ }^{1}$ Chemisches und Veterinäruntersuchungsamt (CVUA) Karlsruhe, Weissenburger Strasse 3, D-76187 Karlsruhe, Germany

Full list of author information is available at the end of the article centésimal' [1]. For this reason, the percentage by volume is also called the French or Gay-Lussac system. (American proof is equal to twice the percentage of volume (i.e. spirits that contain $50 \%$ vol are 100 proof) [2].) The major impetus for standardizing the determination of alcoholic strength was to provide a consistent method for the collection of alcohol taxes. For this reason, the Gay-Lussac system became obligatory in France in 1884 [3]. After the unification of Europe, the indication of alcoholic strength by volume using the symbol '\% vol.' became mandatory in the labelling of alcoholic beverages in the whole European Union (EU) [4]. We will use the nomenclature of European Union laws throughout this article. We specifically refrain from using the term 'ethanol content/con-<smiles></smiles> 
centration' because the measurement of alcoholic strength is based on densimetry, so that a minor amount of alcoholic strength is always constituted by other alcohols (mainly methanol) besides ethanol.

While hydrometer-type alcoholometers are still widely applied in industry, they do not have the accuracy needed in a laboratory setting, especially for the purpose of controlling the relatively strict tolerances allowed by EU law for the indication of alcoholic strength in the labelling (Table 1). For this reason, pycnometric determination of the density has been for a long time the only approved reference method to determine the alcoholic strength in spirits and wines. The densimetric measurement typically has to be preceded by a distillation step (especially for beer, wine and liqueurs), because sugars and other solutes would otherwise lead to false results, as the tables for converting density to alcoholic strength are based on pure water-alcohol mixtures.

In the 1980s, electronic densimetry, which is based on electromagnetically-induced oscillation of a U-shaped glass tube, was introduced into the analysis of alcoholic strength. This method showed similar or better performance in terms of accuracy and precision in comparison to established methods like pycnometry, hydrostatic balance or hydrometry [5-8]. But it took until the year 2000 for the so-called electronic density meters to be introduced into the European community's reference methods for the analysis of spirit drinks [9]. Pycnometry, electronic densimetry and densimetry using hydrostatic balance are also the benchmark methods in the compendium of international methods of wine and must analysis by the International Organisation of Vine and Wine (OIV) [10].

While all these densimetric methods have the advantage of being based on Gay-Lussac's principle and therefore yielding directly comparable results, they are relatively time-consuming. They also require special training of personnel if reproducible results are to be obtained, because there is a risk to cause experimental errors during distillation steps and subsequent densimetric measurements. Some possibilities for automation were previously presented, e.g. in the distillation and/or densimetric steps [11-14], but the sample throughput is still comparably low.

Unsuccessful attempts that did not gain wider distribution in commercial laboratories (besides niche applications) included titration methods [15], enzymatic analysis [16], sequential injection analysis [17] as well as liquid or gas chromatographic methods [18-23]. These methods had basically no advantage over the densimetric reference methods as they were even more complex and labour intensive, and often led to divergent results as they often specifically measure ethanol and not 'alcoholic strength'.

It is no wonder that the next step in the development led to the application of spectroscopic methods that can be used without any sample preparation steps (i.e. without distillation). During the last 20 years, most of the research on alcoholic strength determination was focused on spectroscopy. The earliest infrared (IR) spectroscopic methods typically applied Fourier transform

Table 1: Summary of the tolerances for indication of alcoholic strength by volume in the labelling of alcoholic beverages allowed by European Union Laws

\begin{tabular}{|c|c|c|}
\hline Beverage Group & $\begin{array}{l}\text { Tolerance allowed in the indication of } \\
\text { the alcoholic strength ( } \pm \% \text { vol) }\end{array}$ & Legal Basis \\
\hline Beers (not exceeding 5.5\% vol) & 0.5 & Commission directive $87 / 250 / \mathrm{EC}$ \\
\hline $\begin{array}{l}\text { Beers (exceeding } 5.5 \% \text { vol), ciders, perries, } \\
\text { fruit wines and similar beverages }\end{array}$ & 1.0 & Commission directive $87 / 250 / \mathrm{EC}$ \\
\hline Wine & 0.5 & $\begin{array}{l}\text { Commission directive } \\
607 / 2009 / \mathrm{EC}\end{array}$ \\
\hline $\begin{array}{l}\text { Wine stored in bottles for more than three } \\
\text { years, sparkling wine, semi-sparkling wine }\end{array}$ & 0.8 & $\begin{array}{l}\text { Commission directive } \\
607 / 2009 / \mathrm{EC}\end{array}$ \\
\hline $\begin{array}{l}\text { Beverages containing macerated fruit or } \\
\text { parts of plants }\end{array}$ & 1.5 & Commission directive 87/250/EC \\
\hline $\begin{array}{l}\text { Spirits, beverages not specified otherwise } \\
\text { (e.g., alcopops) }\end{array}$ & 0.3 & Commission directive $87 / 250 / \mathrm{EC}$ \\
\hline
\end{tabular}


infrared (FTIR) or near infrared (NIR) spectrometers and simple linear or multilinear models to derive the alcoholic strength from the ethanol bands, typically of the first or second-order derivative spectra [24-28]. The application of multivariate regression methods (i.e. partial least squares [PLS] regression) allowed researchers to improve the accuracy of the models and to include further parameters besides alcoholic strength [29]. These days, the multicomponent analysis using FTIR instruments specifically developed for beverage analysis allows for the simultaneous analysis of more than 10 compounds in wine, beer, and spirits in less than 2 min per sample [30-39]. A more detailed overview of infrared spectroscopy in alcoholic beverages analysis is provided in the reviews of Garrigues and de la Guardia [40], and of Cozzolino and Dambergs [41].

While infrared spectroscopic techniques are today routinely applied in larger alcohol testing laboratories (e.g., our institute has successfully used FTIR screening for every sample since 2004), the relatively large investment for the instrument currently prohibits the application in smaller laboratories and small-scale manufacturers (e.g. wineries, distilleries, or breweries). In our ongoing investigation of unrecorded alcohol from different countries $[42,43]$, we also sought a portable device that could be used in emerging country settings, but still give results comparable to the reference methods. The infrared spectrometer design patented by Koukolitschek et al. [44] allows the construction of a comparably low-cost instrument. The design was recently implemented in combination with a flow-through cell for alcohol analysis, and is also available in a portable version [45]. The major advantage of this IR sensor is its use of mechanically-fixed components with non-critical alignment, compared to the more complex and movable mechanics of an FTIR sys- tem, which needs continuous laser alignment. In this study, we evaluate this instrument for the analysis of beer, fermenting must, wine, and spirits, and provide a validation in comparison to the densimetric reference methods. Additionally, we evaluate the instrument for the analysis of unrecorded alcohol from different countries.

\section{Experimental}

\section{Instrumentation}

The infrared spectrometer evaluated in this work was the Alcoquick 4000 (Unisensor Sensorsysteme GmbH, Karlsruhe, Germany). The device is available in two versions: laboratory desk-top and portable. We used the portable version, which is installed in an 'Explorer' case for tough operating conditions (pictures of the device are available in [45]). The device uses a patented, spectroscopic multiple-beam measuring procedure, which is based on special wavelengths in the infrared spectrum (see [44] for details on the infrared sensor). Sample, waste, and water hoses are connected to the device and positioned in the appropriate receptacles. When the device is switched on, the system first conducts a reference measurement with water. Next, the sample measurement is started by using the device's touch-screen display. The device samples approximately $40 \mathrm{ml}$ of alcoholic beverage and displays the alcoholic strength in less than $60 \mathrm{~s}$. After that, the next sample can be directly measured. Following each measuring series, a cleansing cycle removes dirt and sample residue from the measuring head. For this, cleaning fluid is used in the sample position and a cleansing cycle is initiated by the software. An overview of the steps is provided in Figure 1.

In the current study, the device was optionally equipped with an oscillation-based density meter. This allows one to simultaneously measure the density of the

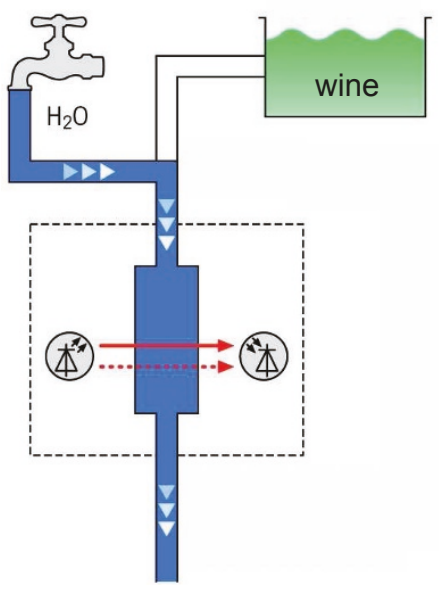

1 Reference measurement

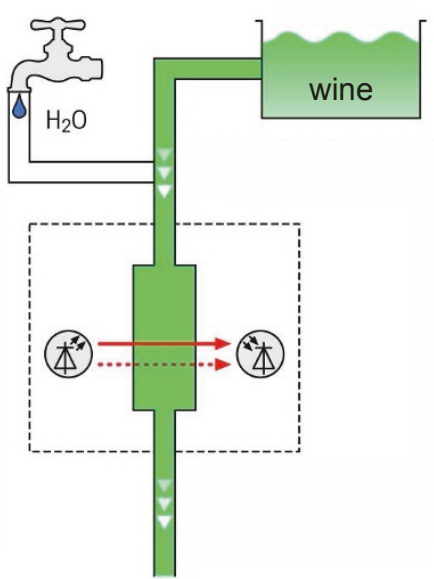

2 Sample measurement

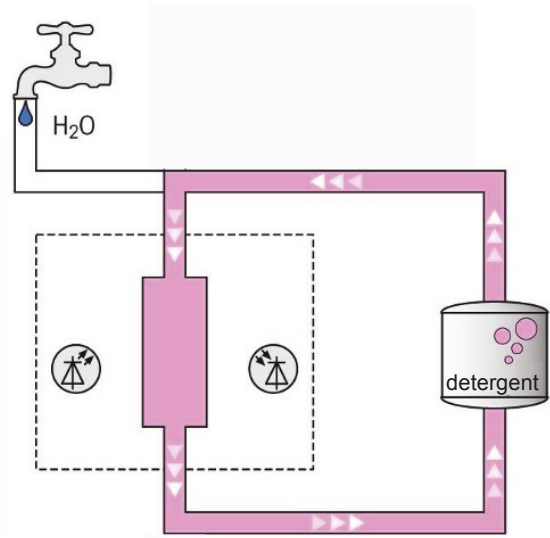

3 Cleansing cycle

Figure 1 Steps for measuring alcoholic beverages using infrared spectroscopy 
sample and calculate further parameters such as the total dry extract of the wine or the original gravity of the beer.

\section{Samples and sample preparation}

Commercial wines, spirits and beers were sampled in the context of official food control by government food inspectors in the German Federal State of Baden-Württemberg between January and October 2009. Wine musts (pressed grapes at the start of fermentation) were sampled by government wine inspectors in wineries in the German wine region 'Baden' in autumn 2009. The fermentations were then conducted on a laboratory scale, and an aliquot of the fermenting must was analysed each day for seven consecutive days.

In general, no sample preparation is necessary for infrared measurement. However, samples containing carbon dioxide, such as beer and must, were prepared by degassing. The degassing was conducted according to the German standard method for the analysis of beer by filtration through fluted filter paper and subsequent ultrasonication for $10 \mathrm{~min}$ [38]. This step also separates solids (e.g. in the grape musts) that could interfere with the measurement.

\section{Comparison data}

For wine, we used results from distillation followed by pycnometry as comparison data. The measurements were conducted according to the OIV method mentioned in the introduction [10]. For spirits and beers, we used FTIR measurement with a laboratory instrument (WineScan FT 120, Foss, Hamburg, Germany) to generate comparison data. The FTIR method has been previously validated and gives data comparable to the densimetric reference procedures [38]. We refrained from using pycnometry as the comparison method for spirits and beers, because we would not have been able to measure the necessary sample numbers due to staff shortage.

\section{Validation and statistics}

To determine the performance of the method, precision as expressed by the relative standard deviation (RSD = standard deviation (SD)/mean $\times 100$ ) of analyzing authentic samples was determined under repeatability

Table 2: Validation results for alcoholic strength measured with infrared spectroscopy

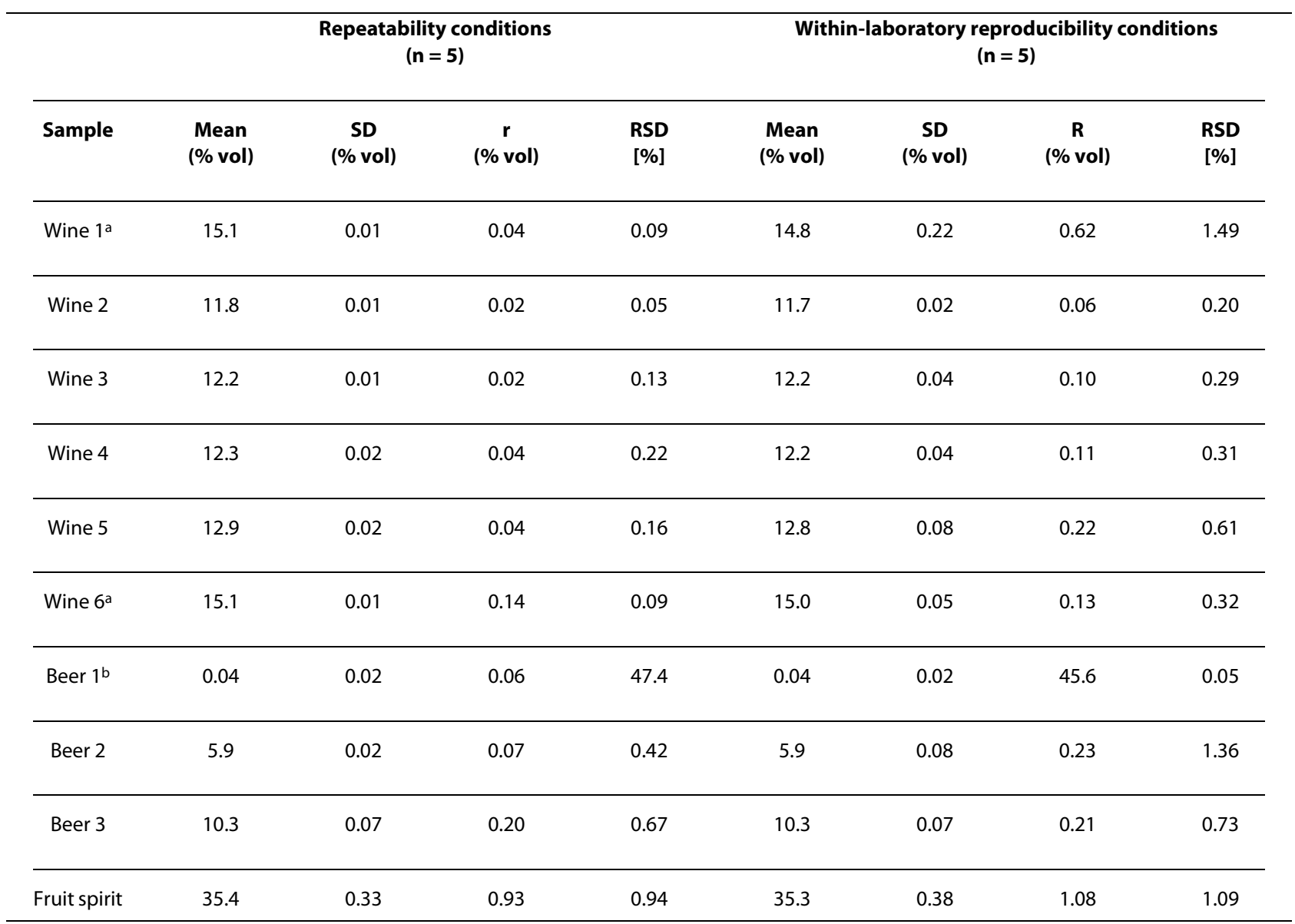

a Dessert/liqueur wines with increased alcoholic strength

${ }^{b}$ Alcohol-free beer 
conditions (same operator, short time intervals), and under within-laboratory reproducibility conditions (different operators, different days). As further validation parameters, the repeatability $(\mathrm{r})$ and reproducibility $(\mathrm{R})$ were calculated as $\mathrm{SD} \times 2.8$. To further check the trueness, 260 samples from the study stack of the CVUA Karlsruhe were measured with both the IR sensor and the comparison method. Linear regression analysis was used to compare both methods. The root mean squared error (RMSE) was calculated to estimate bias. All calculations were conducted with Origin Pro v7.5 software (OriginLab Corporation, Northampton, MA, USA). Statistical significance was assumed at below the 0.05 probability level.

\section{Results and Discussion}

Validation results for wine, beer and spirits

The validation results for the determination of alcoholic strength, density and total dry extract are shown in Tables 2, 3 and 4. The highest precision was reached for the measurement of wines with precisions typically below $0.2 \%$ RSD and an average repeatability of $0.05 \%$ vol. For comparison, the repeatabilities reported by OIV were $0.10 \%$ vol for pycnometry, $0.067 \%$ vol for electronic densimetry, and $0.074 \%$ vol for hydrostatic balance [10]. Therefore, the infrared method performs equally well as or better than the densimetric reference method.

A higher measurement uncertainty was detected for the beers and spirits under study. This can be partly explained by the fact that the device was originally developed for wine analysis, and was only calibrated up to $18 \%$ vol. Using preliminary experiments, we adjusted the wine calibration to higher alcoholic strength using empirical slope-intercept correction. Therefore, the measurement of beverages with a higher alcoholic strength might be improved by implementing a separate calibration in the upper range. This is planned for the next software revision, which will allow the user to choose the type of product prior to measurement (e.g., wine, beer, or spirits). The beverage-specific calibrations are also planned to be amended by implementing other specific parameters (e.g. original gravity of beer, which can be calculated with a formula from the responses of the alcohol sensor and the density; see [45]).

Table 3: Validation results for density measured with density meter (integrated into the infrared spectrometer)

\begin{tabular}{|c|c|c|c|c|c|c|c|c|}
\hline \multirow[b]{2}{*}{ Sample } & \multicolumn{4}{|c|}{$\begin{array}{c}\text { Repeatability conditions } \\
\text { ( } n=5 \text { for wine, } n=10 \text { for beer and spirits) }\end{array}$} & \multicolumn{4}{|c|}{$\begin{array}{l}\text { Within-laboratory reproducibility conditions } \\
\text { ( } n=5 \text { for wine, } n=6 \text { for beer and spirits) }\end{array}$} \\
\hline & $\begin{array}{l}\text { Mean } \\
(\mathbf{k g} / \mathbf{L})\end{array}$ & $\begin{array}{l}\text { SD } \\
(\mathbf{k g} / \mathbf{L})\end{array}$ & $\begin{array}{c}r \\
(\mathbf{k g} / \mathbf{L})\end{array}$ & $\begin{array}{l}\text { RSD } \\
{[\%]}\end{array}$ & $\begin{array}{l}\text { Mean } \\
(\text { kg/L) }\end{array}$ & $\begin{array}{l}\text { SD } \\
(\mathbf{k g} / \mathbf{L})\end{array}$ & $\begin{array}{c}R \\
(\mathbf{k g} / \mathbf{L})\end{array}$ & $\begin{array}{l}\text { RSD } \\
{[\%]}\end{array}$ \\
\hline Wine 1 & 1.0617 & 0.00004 & 0.00011 & 0.0038 & 1.0611 & 0.00063 & 0.00178 & 0.0598 \\
\hline Wine 2 & 1.0125 & 0.00004 & 0.00011 & 0.0040 & 1.0133 & 0.00071 & 0.00198 & 0.0697 \\
\hline Wine 3 & 0.9986 & $<0.00001$ & $<0.00001$ & $<0.00001$ & 0.9993 & 0.00040 & 0.00113 & 0.0403 \\
\hline Wine 4 & 0.9924 & $<0.00001$ & $<0.00001$ & $<0.00001$ & 0.9931 & 0.00042 & 0.00117 & 0.0421 \\
\hline Wine 5 & 0.9948 & $<0.00001$ & $<0.00001$ & $<0.00001$ & 0.9956 & 0.00052 & 0.00146 & 0.0525 \\
\hline Wine 6 & 1.0250 & 0.00004 & 0.00011 & 0.0039 & 1.0257 & 0.00038 & 0.00106 & 0.0370 \\
\hline Beer 1 & 1.0051 & 0.00079 & 0.00222 & 0.0790 & 1.0059 & 0.00138 & 0.00386 & 0.1372 \\
\hline Beer 2 & 1.0074 & 0.00026 & 0.00072 & 0.0257 & 1.0084 & 0.00090 & 0.00253 & 0.0895 \\
\hline Beer 3 & 0.9958 & 0.00195 & 0.00547 & 0.1961 & 0.9976 & 0.00168 & 0.00470 & 0.1681 \\
\hline Eruit spirit & 0.9502 & 0.00068 & 0.00191 & 0.0719 & 0.9510 & 0.00138 & 0.00387 & 0.1453 \\
\hline
\end{tabular}


Table 4: Validation results for total dry extract calculated from results of infrared spectroscopy and density meter

\begin{tabular}{lccccccc}
\hline & \multicolumn{3}{c}{$\begin{array}{c}\text { Repeatability conditions } \\
\text { (n= 5) }\end{array}$} & \multicolumn{1}{c}{ Within-laboratory reproducibility conditions } \\
(n= 5)
\end{tabular}

The relatively large measurement uncertainty of beer \#1 (47\% RSD) can be explained by the fact that this beer was an alcohol-free type with a residual alcohol content of below $0.1 \%$ vol. This is at the lower end of the detection range of the instrument, but our results show that the infrared sensor can still be adequately used to check the alcohol-free requirement of such beverages. (Typically up to $0.5 \%$ vol are tolerated as residual alcohol content.) A normal export-type beer (beer \#2) and a strong beer (beer \#3) showed adequate precision: the standard deviations (even under within-laboratory reproducibility conditions) were below the tolerances for the labelling as detailed in Table 1. A probably explanation about the observation in beer \#3 that the repeatability is slightly larger than the reproducibility could be an insufficient degassing in one of the sample measurements. This stresses the necessity of complete degassing prior to infrared measurement and is the reason why we degas the samples by both filtration and ultrasonication.

Figure 2 shows the relationship between the comparison methods and the infrared method of 260 samples. We measured samples over the whole available range, from alcohol-free beers, beer-based and spirits-based mixed drinks with around 2-3\% vol (so-called alcopops or beerpops), beers (4-8\% vol), wines and fortified wines (10-16\% vol), liqueurs (around 20\% vol), and spirits (30-45\% vol). There were no significant differences between the beverage groups, so all samples were introduced into one regression analysis (Figure 2 ). The regression proved to be linear over the entire range. It should be noted that we have not excluded any outliers from this analysis. For example, one liqueur sample with around $20 \%$ vol was outside of the $95 \%$ prediction limits. This was judged to be due to the high sugar content, viscosity and turbidity of the sample. The slope and intercept of the regression analysis showed a slight deviation from the ideal fit, so that the calibration could be even improved by further slope-intercept correction. As in all multivariate calibrations (e.g. in the previous calibration of the FTIR instrument [38]), this must be treated as an iterative process. However, our results prove that the accuracy of the infrared sensor even on this first stage is generally in good accordance with the previously used procedures and that the results are therefore comparable to the Gay-Lussac

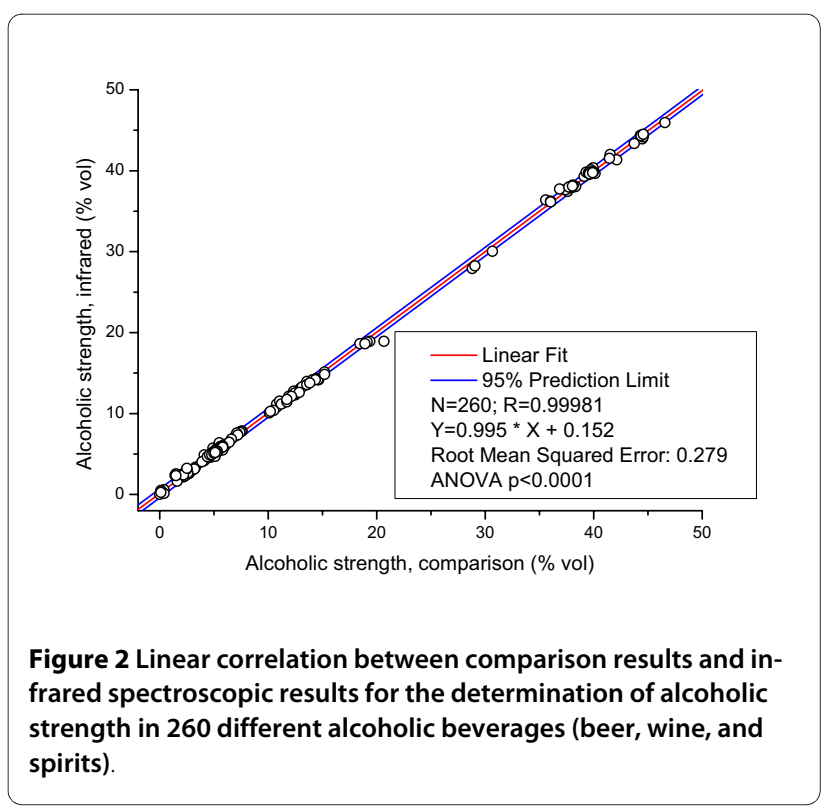




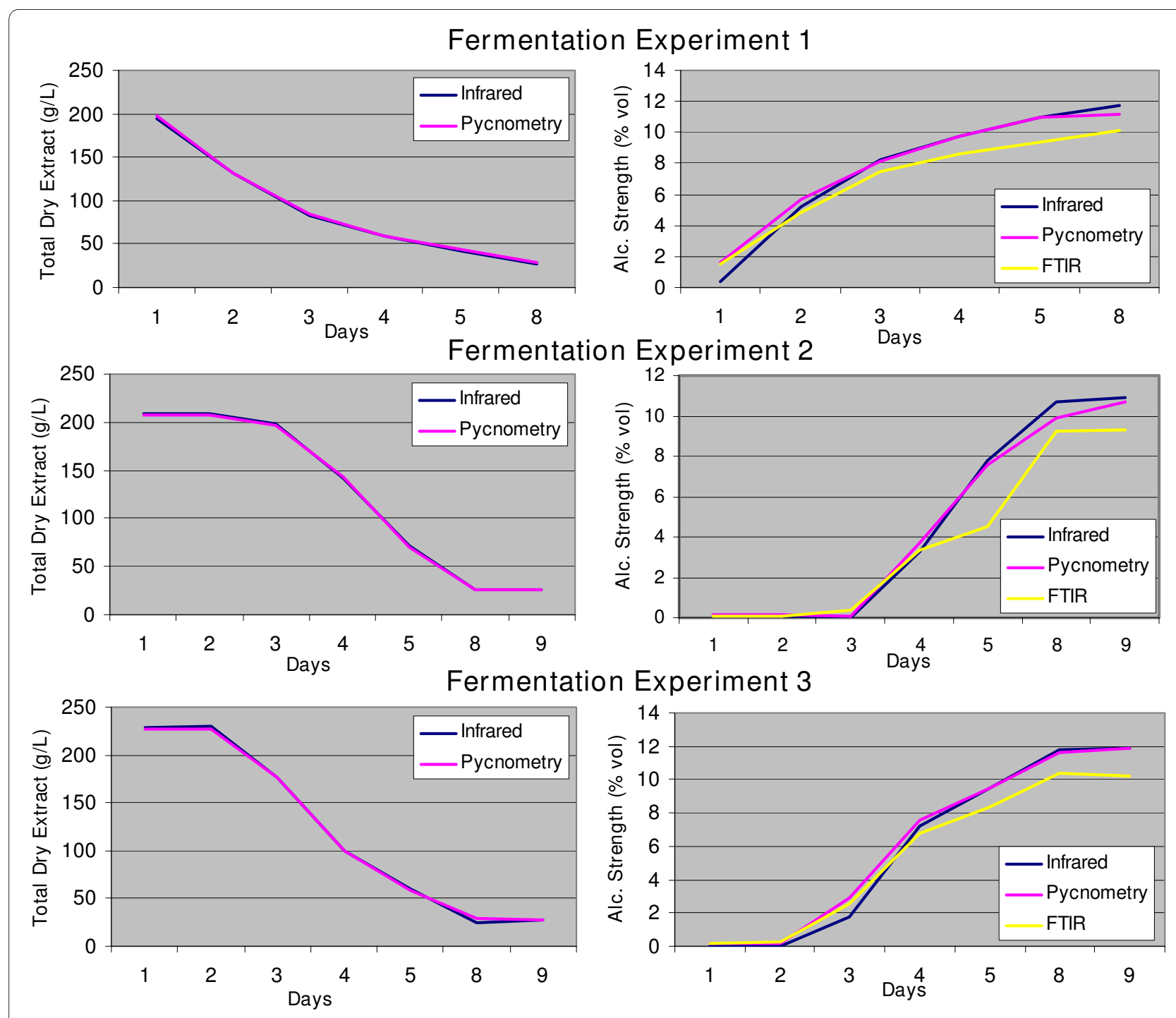

Figure 3 Three wine fermentations were followed using the portable infrared spectrometer in comparison to reference analysis using distillation and pycnometry. The alcoholic strength was also determined using a laboratory FTIR analyzer.

system, which is still the benchmark for every alcoholometric method.

\section{Fermentation experiments}

The results of the fermentation experiments are shown in Figure 3. For all experiments, the curves of infrared spectroscopy overlap with the pycnometric reference measurement. The experiment verifies the observation of the alcohol-free beer that the infrared sensor may be successfully used in the lower range of alcoholic strength. However, for alcoholic strength below $4 \%$ vol larger deviations were observed, which is consistent with the results for alcohol-free beer. A separate matrix calibration for the lower alcohol range could improve the results. Nevertheless, the results show that the sensor can be applied to monitor fermentation processes. For this, the instrument with the optional densimetric measurement is especially useful as it allows for monitoring the decrease of total dry extract (i.e. mainly the decrease of sugars that are fermented to alcohol) in line with the increase of alcohol, and therefore estimating the ending of the fermentation. The portable infrared sensor was better suited for this purpose than our laboratory FTIR instrument, which is based on PLS calibrations. Apparently, the PLS calibration was not optimally suitable for the analysis of musts, as it showed a significantly lower response than the other two methods. This shortcoming could, however, be overcome by modifying the calibration of the FTIR. This does not prove that FTIR/PLS per se is inadequate for the purpose, but it does reveal the inherent problems of matrixdependent multivariate calibrations. As our portable infrared sensor does not use an indirect multivariate cali- 
Table 5: Comparison between analysis of unrecorded alcohols with a laboratory FTIR instrument and the portable infrared spectrometer

\begin{tabular}{|c|c|c|}
\hline Alcohol type, origin & FTIR result (\% vol) & Infrared spectroscopy result (\% vol) \\
\hline Fruit spirit, Croatia & 45.8 & 44.4 \\
\hline Vodka 1, UK & 37.0 & 36.8 \\
\hline Vodka 2, UK & 37.5 & 37.2 \\
\hline Vodka 3, UK & 36.6 & 36.3 \\
\hline Spirit, Poland & 41.5 & 40.9 \\
\hline Spirit, Poland & 44.6 & 45.1 \\
\hline Spirit, Poland & 49.1 & 48.4 \\
\hline Spirit, Poland & 49.4 & 48.7 \\
\hline Spirit, Poland & 48.0 & 48.2 \\
\hline Spirit, Poland & 47.4 & 47.2 \\
\hline Spirit, Poland & 48.7 & 48.7 \\
\hline Spirit, Poland & 39.5 & 40.9 \\
\hline Spirit, Poland & 48.7 & 48.5 \\
\hline
\end{tabular}

bration, it appears to be more robust against unknown matrices such as the fermenting grape musts (for which the device was not originally designed).

\section{Determination of unrecorded alcohols}

Unrecorded alcohol (i.e. non-commercial or illicitly produced alcohol) accounts for approximately one fourth of all alcohol consumed globally [46]. Because these beverages are largely outside government control, there is little information on their production, quality, drinking patterns, and related outcomes. We have discovered that not even the most basic chemical composition such as alcoholic strength is known for these beverages [47]. Limited evidence from pilot studies in Central and Eastern Europe has shown that unrecorded alcohol may contain higher alcoholic strengths than normal recorded alcohol $[48,49]$, and therefore might pose an elevated risk to public health. For this reason, it is important to study the alcoholic strength in unrecorded alcohols. We have previ- ously suggested that representative samples need to be especially studied in emerging countries with comparably high unrecorded consumption [43]. In this context, expensive laboratory measurements such as distillation and pycnometry are not practical, but portable, batterypowered infrared sensors offer a feasible alternative in areas of lower socioeconomic status.

Table 5 shows the results from unrecorded samples from our stock. It appears that the RMSE is higher for the unrecorded samples $(0.68 \% \mathrm{vol})$ than for our recorded samples as shown in Figure $2(0.28 \% \mathrm{vol})$. This may be partly due to the higher alcoholic strengths of the samples, and would probably benefit from a special calibration of the sensor in this range. As well, this difference might also be explained by partial evaporation, since the samples had been opened and stored for a considerable time between both measurements. However, we think that, for evaluating the public health impact of alcohol, a 
measurement error of below $1 \%$ vol is sufficient for the purpose (e.g. to determine if the sample in question has a normal strength around $38-40 \%$ vol or is higher than $50 \%$ vol).

\section{Conclusions}

Compared to densimetric reference methods, infrared sensors are much simpler to handle, and also appear to be suitable for industrial process control. The possibility for mobile use offers opportunities in changing locations or even on-site inspections. Our results show that the device can be successfully applied to labelling control of wine, beer, and spirits, for the monitoring of fermentations, and last but not least, for the evaluation of unrecorded alcohols.

\section{Competing interests}

DWL and RG declare no competing interests. Neither DWL and RG nor the CVUA Karlsruhe received funding from Unisensor Sensorsysteme GmbH. MS, BA, JW and GK are employed by Unisensor Sensorsysteme $\mathrm{GmbH}$, the manufacturer of the instrument described in this article.

\section{Authors' contributions}

DWL conceived of the study, coordinated the work, carried out the analyses of spirits, beer and unrecorded alcohol, and drafted the manuscript. RG carried out the analyses of wines including fermentation experiments and added the aspects of wine analysis to the draft. GK conceived the development of the infrared sensor, and coordinated the technical work. MS and JW designed and built the instrument, while BA developed the software. All authors read and approved the final manuscript.

\section{Acknowledgements}

Martina Fuchs, Hannelore Heger, Sonja Klein, and Ursula Konrad are thanked for their excellent technical assistance.

The sampling of some of the unrecorded alcohols studied in this paper conducted by DWL was financed by the European Commission Seventh Framework Programme Project AMPHORA (Alcohol Measures for Public Health Research Alliance), project number 223059, granted to the Hospital Clinic de Barcelona http://www.amphoraproject.net. Otherwise, no funding was specific to the production of this manuscript. The salaries for authors were provided by the affiliated organizations.

\section{Author Details}

${ }^{1}$ Chemisches und Veterinäruntersuchungsamt (CVUA) Karlsruhe, Weissenburger Strasse 3, D-76187 Karlsruhe, Germany and 2Unisensor Sensorsysteme GmbH, Am Sandfeld 11c, D-76149 Karlsruhe, Germany

Received: 16 December 2009 Accepted: 23 March 2010

Published: 23 March 2010

\section{References}

1. Gay-Lussac J-L: Instruction pour l'usage de l'alcoomètre centésimal et des tables qui l'accompagnent 1824 [http://books.google.com/ books?id=3ewMAAAAYAAJ]. Paris, France: Chez M. Collardeau

2. IARC: IARC Monographs on the Evaluation of Carcinogenic Risks to Humans Volume 44. Alcohol Drinking. Lyon, France; 1988.

3. de Brevans J: The manufacture of liquors and preserves New York, NY: Munn \& Co; 1893.

4. European Commission: Commission Directive 87/250/EEC on the indication of alcoholic strength by volume in the labelling of alcoholic beverages for sale to the ultimate consumer. Off J Europ Comm 1987, L113:57-58.

5. Strunk DH, Hamman JW, Timmel BM: Determination of proof of distilled alcoholic beverages, using an oscillating U-tube density meter. JAOAC 1979, 62:653-658.
6. Mark FG, Vaughn TE: Determination of proof of alcoholic beverages using oscillating U-tube density meter. J AOAC 1980, 63:970-972.

7. Kovár J: Oscillating U-tube density meter determination of alcoholic strength: analysis of paramter errors. J AOAC 1981, 64:1424-1430.

8. Brereton P, Hasnip S, Betrand A, Wittkowski R, Guillou C: Analytical methods for the determination of spirit drinks. Trends Anal Chem 2003, 22:19-25.

9. European Commission: Commission Regulation (EC) No 2870/2000 laying down Community reference methods for the analysis of spirits drinks. Off J Europ Comm 2000, L333:20-46.

10. OIV: Compendium of international methods of wine and must analysis. Edition 2009 Paris, France: International Organisation of Vine and Wine; 2009.

11. Strunk DH: Rapid method for the determination of proof of alcoholic products containing dissolved solids. J AOAC 1972, 55:13-14.

12. Lachenmeier DW, Sviridov O, Frank W, Athanasakis C: Rapid determination of ethanol in spirit drinks using steam distillation and densitometry. Deut Lebensm Rundsch 2003, 99:439-444.

13. Lachenmeier DW, Burri PA, Fauser T, Frank W, Walch SG: Rapid determination of alcoholic strength of egg liqueur using steam distillation and oscillation-type densimetry with peristaltic pumping. Anal Chim Acta 2005, 537:377-384

14. Lachenmeier DW, Walch SG, Kessler W: Using experimental design to optimise precision of steam distillation for determining alcoholic strength in spirits. Eur Food Res Technol 2006, 223:261-266.

15. Rebelein H: Schnellmethode zur Bestimmung des Alkoholgehaltes in Likören und Branntweinen. Alkohol-Ind 1975, 16:376-378.

16. Beutler H-O, Michal G: Neue Methode zur enzymatischen Bestimmung von Äthanol in Lebensmitteln. ZAnal Chem 1977, 284:113-117.

17. Fletcher PJ, van Staden JF: Determination of ethanol in distilled liquors using sequential injection analysis with spectrophotometric detection. Anal Chim Acta 2003, 499:123-128.

18. Pietsch H-P, Oehler R, Kasprick D: Gaschromatographische Bestimmung von Äthanol in Spirituosen. Nahrung 1968, 12:885-887.

19. Matthes D: Alkoholbestimmungen mittels DampfraumGaschromatographie - eine einfache, schnelle Methode für den Routinebetrieb. Branntweinwirtsch 1981, 121:370-372.

20. Kovár J: Determination of alcoholic strength in alcoholic beverages by gas-solid chromatography. J Chromatogr 1985, 333:389-403.

21. Wang ML, Wang JT, Choong YM: Simultaneous quantification of methanol and ethanol in alcoholic beverage using a rapid gas chromatographic method coupling with dual internal standards. Food Chem 2004, 86:609-615.

22. Martin E, ladaresta V, Giacometti JC, Vogel J: Ethanol determination by HPLC in alcoholic beverages. Mitt Geb Lebensmittelunters Hyg 1986 77:528-534

23. Buckee GK, Mundy AP: Determination of Ethanol in Beer by Gas Chromatography (Direct Injection)-Collaborative Trial. J Inst Brew 1993, 99:381-384.

24. López Mahía P, Simal Gándara J, Paseiro Losada P: Validation of Ethanol Determination in Alcoholic Beverages by Infrared Spectrophotometry Using Orthogonal and Derivative Functions to Correct for WaterAbsorption. Vib Spectrosc 1992, 3:133-138.

25. Gallignani M, Garrigues S, de la Guardia M: Direct Determination of Ethanol in All Types of Alcoholic Beverages by Near-Infrared Derivative Spectrometry. Analyst 1993, 118:1167-1173

26. Gallignani M, Garrigues S, delaGuardia M: Stopped-Flow Near-Infrared Spectrometric Determination of Ethanol and Maltose in Beers. Anal Chim Acta 1994, 296:155-161.

27. Gallignani M, Garrigues S, de la Guardia M: Derivative Fourier-Transform Infrared Spectrometric Determination of Ethanol in Beers. Analys 1994, 119:1773-1778.

28. Gallignani M, Garrigues S, de la Guardia M: Derivative Fourier-Transform Infrared Spectrometric Determination of Ethanol in Alcoholic Beverages. Anal Chim Acta 1994, 287:275-283.

29. Maudoux M, Yan SH, Collin S: Quantitative analysis of alcohol, real extract, original gravity, nitrogen and polyphenols in beers using NIR spectroscopy. J Near Infrared Spectrosc 1998, 6:A363-A366.

30. Patz CD, David A, Thente K, Kürbel P, Dietrich H: Wine analysis with FTIR spectrometry. Vitic Enol Sci 1999, 54:80-87. 
31. Kupina SA, Shrikhande AJ: Evaluation of a Fourier transform infrared instrument for rapid quality-control wine analyses. Am J Enol Vitic 2003, 54:131-134

32. Patz CD, Blieke A, Ristow R, Dietrich H: Application of FT-MIR spectrometry in wine analysis. Anal Chim Acta 2004, 513:81-89.

33. Urbano-Cuadrado M, Luque de Castro MD, Pérez-Juan PM, García-Olmo J, Gómez-Nieto MA: Near infrared reflectance, spectroscopy and multivariate analysis in enology - Determination or screening of fifteen parameters in different types of wines. Anal Chim Acta 2004, 527:81-88.

34. Iñón FA, Llario R, Garrigues S, de la Guardia M: Development of a PLS based method for determination of the quality of beers by use of NIR: spectral ranges and sample-introduction considerations. Anal Bioanal Chem 2005, 382:1549-1561.

35. Cocciardi RA, Ismail AA, Sedman J: Investigation of the potential utility of single-bounce attenuated total reflectance Fourier transform infrared spectroscopy in the analysis of distilled liquors and wines. J Agric Food Chem 2005, 53:2803-2809.

36. Llario R, Iñón FA, Garrigues S, de la Guardia M: Determination of quality parameters of beers by the use of attenuated total reflectance-Fourier transform infrared spectroscopy. Talanta 2006, 69:469-480.

37. Iñón FA, Garrigues S, de la Guardia M: Combination of mid- and nearinfrared spectroscopy for the determination of the quality properties of beers. Anal Chim Acta 2006, 571:167-174

38. Lachenmeier DW: Rapid quality control of spirit drinks and beer using multivariate data analysis of Fourier transform infrared spectra. Food Chem 2007, 101:825-832.

39. Arzberger U, Lachenmeier DW: Fourier Transform Infrared Spectroscopy with Multivariate Analysis as a Novel Method for Characterizing Alcoholic Strength, Density, and Total Dry Extract in Spirits and Liqueurs. Food Anal Methods 2008, 1:18-22.

40. Garrigues S, de la Guardia M: Methods for the vibrational spectroscopy analysis of beers. In Beer in Health and Disease Prevention Edited by: Preedy VR. Amsterdam: Elsevier; 2009:943-961.

41. Cozzolino D, Dambergs RG: Wine and Beer. In Infrared Spectroscopy for Food Quality Analysis and Control Edited by: Sun D-W. Burlington, MA: Elsevier; 2009:377-397.

42. Lachenmeier DW, Rehm J: Unrecorded alcohol: a threat to public health? Addiction 2009, 104:875-877.

43. Rehm J, Kanteres F, Lachenmeier DW: Unrecorded consumption, quality of alcohol and health consequences. Drug Alcohol Rev 2010 [http:// www3.interscience.wiley.com/journal/123243991/abstract].

44. Koukolitschek K, Krieg G, Maier W: Optical absorption spectrometer used for industrial application provides full range spectrum from a single narrow band interference filter. German Patent 2000, DE 19849847 A1:1-8.

45. Lachenmeier DW, Godelmann R, Steiner M, Ansay B, Weigel J, Krieg G: Infrarotsensor zur Schnellbestimmung des Alkoholgehalts. Deut Lebensm Rundsch 2009, 105(Suppl):4-6.

46. Rehm J, Mathers C, Popova S, Thavorncharoensap M, Teerawattananon Y, Patra J: Global burden of disease and injury and economic cost attributable to alcohol use and alcohol-use disorders. Lancet 2009, 373:2223-2233.

47. Lachenmeier DW, Rehm J, Gmel G: Surrogate alcohol: what do we know and where do we go? Alcohol Clin Exp Res 2007, 31:1613-1624.

48. Lachenmeier DW, Sarsh B, Rehm J: The composition of alcohol products from markets in Lithuania and Hungary, and potential health consequences: A pilot study. Alcohol Alcohol 2009, 44:93-102.

49. Lachenmeier DW, Ganss S, Rychlak B, Rehm J, Sulkowska U, Skiba M, Zatonski W: Association between quality of cheap and unrecorded alcohol products and public health consequences in Poland. Alcohol Clin Exp Res 2009, 33:1757-1769.

\section{doi: 10.1186/1752-153X-4-5}

Cite this article as: Lachenmeier et al., Rapid and mobile determination of alcoholic strength in wine, beer and spirits using a flow-through infrared sensor Chemistry Central Journal 2010, 4:5

Publish with ChemistryCentral and every
scientist can read your work free of charge
"Open access provides opportunities to our
colleagues in other parts of the globe, by allowing
anyone to view the content free of charge."
W. Jeffery Hurst, The Hershey Company.
- available free of charge to the entire scientific community
- peer reviewed and published immediately upon acceptance
- cited in PubMed and archived on PubMed Central
- yours - you keep the copyright
submit your manuscript here:
http://www.chemistrycentral.com/manuscript/

